\title{
Hemodialysis Increases Apparent Diffusion Coefficient of Brain Water in Nephrectomized Rats Measured by Isotropic Diffusion-weighted Magnetic Resonance Imaging
}

\author{
Jean-Philippe Galons, ${ }^{\text {Ted Trouard, }}{ }^{\ddagger}$ Arthur F. Gmitro, ${ }^{\ddagger}$ and Yeong-Hau H. Lien ${ }^{\star}$ \\ Departments of*Medicine and ${ }^{\ddagger}$ Radiology, University of Arizona, Tucson, Arizona 85724
}

\begin{abstract}
The nature of brain edema in dialysis disequilibrium syndrome (DDS) was investigated by diffusion-weighted magnetic resonance imaging (DWI). DWI was performed on normal or bilaterally nephrectomized rats before, and immediately after, hemodialysis. Hemodialysis was performed with a custom-made dialyzer (surface area $150 \mathrm{~cm}^{2}$ ) against a bicarbonate-buffered bath for $90 \mathrm{~min}$ with or without $\mathbf{7 0}$ $\mathrm{mM}$ urea. Hemodialysis with non-urea bath decreased plasma urea by $21 \mathrm{mM}$, and plasma osmolality by 22 mos$\mathrm{mol} / \mathrm{kg} \mathrm{H}_{2} \mathrm{O}$, and increased brain water content by $8.0 \%$ (all $P<0.05$ ), while hemodialysis with urea bath did not affect plasma urea, osmolality, or brain water content. Three sets of axial DWI images of the brain were obtained at different gradient weighing factors with an in-plane resolution of $0.39 \mathrm{~mm}^{2}$. The apparent diffusion coefficient $\left(\mathrm{D}_{\text {app }}\right)$ of the brain water was not affected by bilateral nephrectomy, or by hemodialysis in normal rats. In nephrectomized rats, brain $\mathrm{D}_{a p p}$ was significantly increased after dialysis with non-urea bath $\left(1.15 \pm 0.08\right.$ vs $\left.0.89 \pm 0.07 \times 10^{-9} \mathrm{~m}^{2} / \mathrm{sec}, P<0.01\right)$. No significant changes of brain water $D_{a p p}$ could be observed after dialysis with urea bath. The increased $\mathrm{D}_{a p p}$ associated with DDS indicates that brain extracellular water increases and/or intracellular water decreases after hemodialysis. Our results strongly suggest that the brain edema induced by hemodialysis in uremic rats is due to interstitial edema rather than cytotoxic edema. Furthermore, our results support a primary role for the "reverse urea effect" in the pathogenesis of brain edema in DDS. DWI may be a useful diagnostic tool for DDS in patients with end-stage renal disease. $(J$. Clin. Invest. 1996. 98:750-755.) Key words: nuclear magnetic resonance $\cdot$ uremia $\bullet$ brain edema
\end{abstract}

Portions of this work were presented at the 28th meeting of the American Society of Nephrology in San Diego, CA on 5-8 November 1995. Portions of this work have appeared in abstract form (J. Am. Soc. Nephrol. 6:530).

Address correspondence to Yeong-Hau H. Lien, Department of Medicine, Renal Section, University of Arizona Health Sciences Center, Tucson, AZ 85724. Phone: 520-626-6370; FAX: 520-626-2024; E-mail: lien@aruba.ccit.arizona.edu

Received for publication 6 February 1996 and accepted in revised form 30 May 1996.

J. Clin. Invest.

(C) The American Society for Clinical Investigation, Inc. 0021-9738/96/08/0750/06 \$2.00

Volume 98, Number 3, August 1996, 750-755

\section{Introduction}

Dialysis disequilibrium syndrome (DDS) ${ }^{1}$ in patients receiving hemodialysis, as first described by Kennedy et al. (1), has been observed for more than $30 \mathrm{yr}$. The syndrome may include symptoms such as headache, nausea, emesis, blurring of vision, muscular twitching, disorientation, hypertension, tremors, seizures, and coma (2). Up to now, there has been no diagnostic test for DDS and its diagnosis in patients with end-stage renal diseases is mainly based on the exclusion of other possible central nervous disorders (3). It is clear that most of the clinical manifestations of dialysis syndrome are mainly due to brain swelling occurring as a consequence of the dialysis procedure $(2,4)$. The nature of brain edema associated with DDS remains a controversial issue. It has been classified as a cytotoxic edema by Fishman and Chan (5) and as an osmotic edema by Milhorat (6). Cytotoxic edema results from a disturbance of cell volume regulation sufficient to produce an abnormal increase of fluid within the cytoplasm of cells, while an osmotic edema is characterized by an increase in the extracellular space due to an osmotic gradient $(5,6)$.

Moreover, there have been conflicting studies concerning the physiological mechanisms that lead to the formation the edema in DDS. Pappius et al. introduced the "reverse urea hypothesis" postulating that a significant urea gradient between blood and brain after dialysis was responsible for the inflow of water to the brain (4). On the other hand, Arieff concluded that the formation of idiogenic osmoles was responsible for the edema formation (2). The present work using diffusionweighted magnetic resonance images (DWI) was undertaken to characterize the nature and the mechanisms of formation of brain edema occurring in rats with DDS.

The apparent diffusion coefficient $\left(\mathrm{D}_{a p p}\right)$ measured by DWI is sensitive to the hydrodynamic environment of tissue water $(7,8)$. Several DWI sequences have been developed that enable the measurement of the $\mathrm{D}_{a p p}$ of the brain water. Significant use of this technique has already been made in the imaging and diagnosis of stroke (9-12). Most DWI sequences are based on either a spin echo or a stimulated echo experiment to which diffusion-sensitizing gradients are added. A very useful sequence was introduced recently by Mori and van Zijl (13). This sequence weights image intensity to the trace of the diffusion tensor $\left(\mathrm{D}_{x x}+\mathrm{D}_{y y}+\mathrm{D}_{z z}\right)$ within a single data acquisition step. As the trace of the diffusion tensor is invariant upon coordinate rotation, the $\mathrm{D}_{\text {app }}$ obtained from this sequence is independent of patient orientation. This is particularly important when measuring $\mathrm{D}_{a p p} \mathrm{~s}$ in tissue with anisotropic structures

1. Abbreviations used in this paper: $\mathrm{D}_{a p p}$, apparent diffusion coefficient; DDS, dialysis disequilibrium syndrome; DWI, diffusionweighted images; ROI, region of interest. 
such as gray and white matter of the brain. Using this sequence, we monitored the diffusion of brain water in nephrectomized rats before and after hemodialysis and in the presence or absence of urea in the dialysis bath. The results were compared with those observed in normal rats after hemodialysis with non-urea bath.

\section{Methods}

Animal models. All studies received approval from the University of Arizona Animal Care and Use Committee. Male Sprague-Dawley rats (Holtzmann Co., Madison, WI) weighing $\sim 300 \mathrm{~g}$ were used in the study. Animals were divided into five groups: $(a)$ normal controls; (b) normal rats receiving hemodialysis; (c) uremic rats studied $2 \mathrm{~d}$ after bilateral nephrectomy; $(d)$ uremic rats receiving hemodialysis $2 \mathrm{~d}$ after nephrectomy with standard bicarbonate-buffered dialysate; and (e) uremic rats receiving hemodialysis with urea-containing dialysate. Animals in groups $c, d$, and $e$ underwent bilateral nephrectomy under pentobarbital anesthesia (50 $\mathrm{mg} / \mathrm{kg}$ i.p.), and groups $d$ and $e$ underwent dialysis and imaging $2 \mathrm{~d}$ later. Bicarbonate-buffered dialysate was used for groups $b$ and $d$, while bicarbonate-buffered dialysate with an addition of urea was used for group $e$. The groups of normal (a) and nephrectomized (c) rats that did not undergo hemodialysis were used mainly for the measurement of predialysis brain water content, which is otherwise not available in rats undergoing hemodialysis.

Hemodialysis. Rats were hemodialyzed against bicarbonatebuffered bath as described by Silver et al. (14) with minor modifications. The dialysate contained $(\mathrm{mM})$ : sodium 142 , bicarbonate 35 , potassium 3 , chloride 115 , calcium 2 , magnesium 0.75 , and glucose 11 . In the group of dialysis with a urea-containing bath, the dialysate contained $70 \mathrm{mM}$ urea, which was approximately the average plasma urea value of uremic rats. We did not adjust urea concentration according to individual urea levels because the individual difference was not large enough to generate a significant drop of plasma urea level after dialysis (Table I). The dialysate temperature was maintained at $37^{\circ} \mathrm{C}$. Hemodialysis using a custom-made cuprophane hollow-fiber dialyzer (surface area $150 \mathrm{~cm}^{2}$ ) was performed via a femoral artery and vein in rats anesthetized with pentobarbital. Catheters (PE50; Becton Dickinson, Inc., Parsippany, NJ) were placed in vessels and connected to a dialyzer. Blood and dialysate were circulated in a counter-current fashion using roller pumps. The dialyzer and extracorporeal circuit was primed with $3 \mathrm{ml}$ blood from normal rats. Heparin was given in a 2,000-U bolus, followed by a 1,000-U/h infusion into the arterial line to prevent dialyzer clotting. Dialysate flow rate was $40 \mathrm{ml} / \mathrm{min}$ and blood flow $4 \mathrm{ml} / \mathrm{min}$ to achieve a rapid clearance of urea. During dialysis, blood pressure was monitored with a transducer that was connected to the femoral arterial line. There was no ultrafiltration and the animals were kept at a constant weight. Any significant decrease of blood pressure or body weight was treated with intravenous saline infusion. Dialysis was performed for $90 \mathrm{~min}$. Rats with stable hemodynamics during the hemodialysis procedure were used for the DWI studies. At the end of hemodialysis, $0.5 \mathrm{ml}$ blood was obtained from the arterial line and the rat was disconnected from the dialysis circuit. The $\mathrm{D}_{a p p}$ was then measured using the isotropic DWI technique. Immediately after DWI, rats were killed by decapitation. The brain was rapidly removed from the skull. A cerebral hemisphere was weighed and dried at $100^{\circ} \mathrm{C}$ for $24 \mathrm{~h}$, and then reweighed to determine water content (15). Plasma urea level was determined by the urease method (16), and plasma osmolality by freezing-point depression (Micro-osmometer; Advanced Instruments Inc., Needham Heights, MA).

Isotropic diffusion-weighted imaging. For the imaging experiments, the rats were anesthetized and placed in a prone position on the nuclear magnetic resonance (NMR) probe. Special care was taken to prevent motion. The head was strongly strapped to the probe or placed in a custom-made head restraint. A teeth holder was added to prevent any motion during the DWI experiment. The 90min dialysis was performed outside the NMR machine with the rat on the probe. Typically, no more than 5 to 6 min were necessary to start the postdialysis DWI experiments. All images were acquired on a Biospec system (4.7 T/40 cm; Bruker, Karlsruhe, Germany) equipped with an ASPECT 3000 computer running the imaging software (TOMIKON; Bruker). A standard $5 \mathrm{~cm}$, double tuned, single turn ${ }^{1} \mathrm{H} /{ }^{\beta 1} \mathrm{P}$ surface coil was used as a transmitter and receiver (Bruker). The DWI brain images of normal and nephrectomized rats before and after dialysis were obtained with the sequence shown in Fig. 1. Because motion is always a concern in DWI, the acquisition of "navigator" echoes was included in the DWI sequence. Navigator echoes allow the postacquisition correction for bulk animal motion $(17,18)$. The four pairs of bipolar diffusion gradient pulses are shaded in gray in Fig. 1. Before the in vivo experiments, the sequence was calibrated.

Table I. Physiological and Biochemical Parameters before and after Hemodialysis

\begin{tabular}{|c|c|c|c|c|c|}
\hline Rat groups & $\begin{array}{c}\text { Normal } \\
\text { nondialyzed }\end{array}$ & $\begin{array}{l}\text { Normal } \\
\text { dialyzed }\end{array}$ & $\begin{array}{l}\text { Nephrectomized } \\
\text { nondialyzed }\end{array}$ & $\begin{array}{l}\text { Nephrectomized } \\
\text { dialyzed w/o urea }\end{array}$ & $\begin{array}{l}\text { Nephrectomized } \\
\text { dialyzed with urea }\end{array}$ \\
\hline & $n=6$ & $n=6$ & $n=6$ & $n=6$ & $n=5$ \\
\hline \multicolumn{6}{|l|}{ Body weight (gm) } \\
\hline Before dialysis & $296 \pm 8$ & $304 \pm 11$ & $294 \pm 9$ & $298 \pm 11$ & $290 \pm 4$ \\
\hline After dialysis & - & $303 \pm 11$ & - & $298 \pm 11$ & $289 \pm 4$ \\
\hline \multicolumn{6}{|c|}{ Mean arterial blood pressure $(\mathrm{mmHg})$} \\
\hline Before dialysis & - & $96 \pm 4$ & - & $91 \pm 4$ & $86 \pm 5$ \\
\hline After dialysis & - & $93 \pm 4$ & - & $93 \pm 3$ & $85 \pm 6$ \\
\hline \multicolumn{6}{|l|}{ Plasma urea (mM) } \\
\hline Before dialysis & $9 \pm 2$ & $8 \pm 3$ & $74 \pm 7 *$ & $71 \pm 5^{*}$ & $72 \pm 4 *$ \\
\hline After dialysis & - & $10 \pm 4$ & - & $50 \pm 4$ ** & $71 \pm 4 *$ \\
\hline \multicolumn{6}{|c|}{ Plasma osmolality (mosmol/kg) } \\
\hline Before dialysis & $290 \pm 3$ & $289 \pm 7$ & $361 \pm 8^{*}$ & $356 \pm 10 *$ & $354 \pm 8^{*}$ \\
\hline After dialysis & - & $293 \pm 9$ & - & $334 \pm 8^{* * \frac{1}{+}}$ & $350 \pm 9 *$ \\
\hline \multicolumn{6}{|c|}{ Brain water content (liter/kg dry wt) } \\
\hline Before dialysis & $3.69 \pm 0.03$ & - & $3.62 \pm 0.06$ & - & - \\
\hline After dialysis & - & $3.67 \pm 0.04$ & - & $3.91 \pm 0.08^{* *}$ & $3.63 \pm 0.10$ \\
\hline
\end{tabular}

Values are means \pm SEM. ${ }^{*} P<0.01$ vs normal; ${ }^{\ddagger} P<0.05$ vs nephrectomized before dialysis, or nephrectomized after dialysis with urea. 


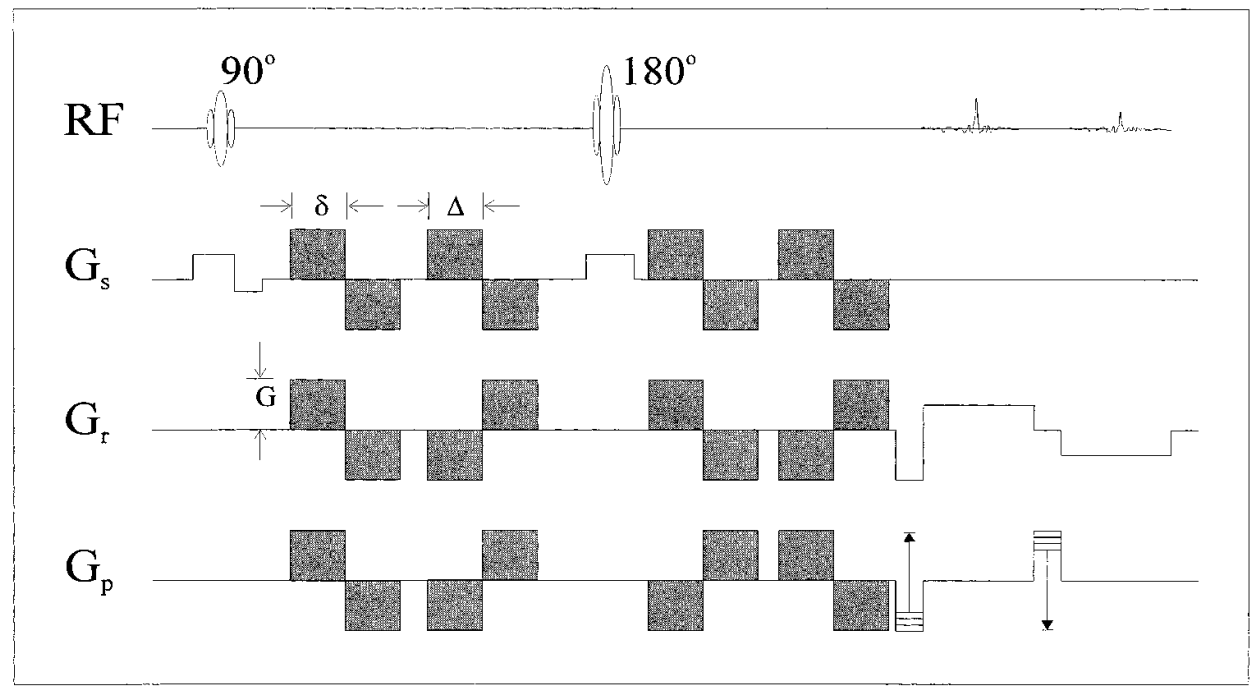

Figure 1. Spin-echo imaging sequence with isotropic diffusionweighted and navigator echo for motion correction. The shadowed gradients are the diffusion gradients. The other gradients are slice select $(\mathrm{z})$, readout $(\mathrm{x})$, and phase encoding (y) imaging gradients. The first echo is the image spin-echo and the second echo is the navigator echo. The amount of diffusion weighing can be adjusted by changing $\Delta, \delta$, or $\mathrm{G}$ (see Methods).

The correct values for the diffusion coefficients of standard samples (water, acetone, and DMSO) were determined.

For each normal or nephrectomized rat, three sets of multislice images were recorded using three different diffusion gradient strengths, both before and after dialysis. The $b$ values for these diffusion gradients were $0.009 \times 10^{9} \mathrm{~s} / \mathrm{m}^{2}, 0.231 \times 10^{9} \mathrm{~s} / \mathrm{m}^{2}$, and $0.921 \times 10^{9}$ $\mathrm{s} / \mathrm{m}^{2}$, respectively. The images were acquired with an echo time of 96 $\mathrm{ms}$, a repetition time of $0.640 \mathrm{~s}$ and four scans. Diffusion time $(\Delta)$ was $10 \mathrm{~ms}$, and diffusion gradient pulse length was $8 \mathrm{~ms}$. The matrix size was $64 \times 64$ corresponding to an "in plane resolution" of $0.39 \mathrm{~mm}^{2}$, with a slice thickness of $5 \mathrm{~mm}$. The total scan time was $2.45 \mathrm{~min}$ per image set.

$\mathrm{D}_{\text {app }}$ s were calculated at each pixel by fitting the intensity values $S$ to the exponential decay given by Eq. 1,

$S=S_{0} e^{-b D_{a p p}}$

where $S_{0}$ is the pixel intensity without diffusion weighing and $D_{a p p}$ is the apparent diffusion coefficient. The gradient weighing factor $b$ is defined by

$b=4 \gamma^{2} G^{2} \delta^{2}\left(\Delta-\frac{\delta}{3}\right)$

where $\gamma$ is the gyromagnetic ratio, $G$ is the gradient strength, $\delta$ is the duration of a diffusion gradient, and $\Delta$ is the time separation between balanced gradient pairs. The factor of 4 in Eq. 2 arises from the four pairs of bipolar gradient pulses in the imaging sequence (Fig. 1). Fitting was accomplished using a standard conjugate gradient minimization routine. The calculated diffusion maps were generated using the program Khoros, (Khoral Research Inc,. Albuquerque, NM), running on a DEC Station-3100 (Digital Equipment Corp., Nashua, NH).

Selection of region of interest. Two regions of 15 to 20 pixels were selected from the left and right sides of the cerebral cortex in the middle slice for calculations of the corresponding $\mathrm{D}_{a p p}$. The first and third slices were examined to rule out the inclusion of invagination of macroscopic cerebro-spinal fluid (CSF)-containing space. No effort was made to discriminate between gray and white matters due to low resolution. The selection of regions of interest (ROIs) was always performed using the image with the highest contrast (lowest $b$ value). To verify that no significant CSF space was included in the ROI, a smaller ROI (10 pixels) was selected within the original ROI. If there is a major CSF contamination, because the CSF space in the outer portions of the larger ROIs should be greater than the smaller, the $\mathrm{D}_{\text {app }}$ of the larger ROI should be higher than that of the smaller ROI. We found that $\mathrm{D}_{a p p}$ was not different between the larger and smaller ROIs either before $\left(0.89 \pm 0.07\right.$ vs $\left.0.86 \pm 0.10 \times 10^{-9} \mathrm{~m}^{2} / \mathrm{s}\right)$ or after $\left(1.15 \pm 0.08\right.$ vs $\left.1.13 \pm 0.12 \times 10^{-9} \mathrm{~m}^{2} / \mathrm{s}\right)$ hemodialysis. These observations confirmed that the original ROIs did not contain the CSF space surrounding the brain.

Statistics. Data are expressed as means \pm SD. Differences among groups for $\mathrm{D}_{a p p}$ values, brain water content, and plasma analyses were evaluated using ANOVA. The Student's paired $t$ test was used to assess differences among prenephrectomy, predialysis, and postdialysis values within a group. Significance was accepted at the $P<0.05$ level.

\section{Results}

All rats survived bilateral nephrectomy up to $48 \mathrm{~h}(n=21)$. Since hypoxia may affect brain water $\mathrm{D}_{a p p}$, only rats with stable blood pressure throughout the dialysis procedure were used for $\mathrm{D}_{\text {app }}$ measurement. 11 out of 21 nephrectomized rats and 6 out of 7 normal rats that underwent hemodialysis met this criteria and were analyzed. There were no significant changes in both body weight and mean arterial blood pressure after dialysis (Table I). Causes for hemodynamic instability were multifactorial, including anesthesia, blood leakage, and clotting.

Plasma analyses and brain water content. Plasma urea level, osmolality, and brain water content (means \pm SEM) in normal and nephrectomized rats with and without hemodialysis are given in Table I. Hemodialysis did not affect plasma urea level or osmolality in normal rats dialyzed with non-urea dialysate, or in nephrectomized rats hemodialyzed with urea-containing dialysate. However, in nephrectomized rats undergoing a dialysis with a non-urea bath, plasma urea decreased from $71 \pm 5$ to $50 \pm 4 \mathrm{mM}$, and osmolality decreased from $356 \pm 10$ to $334 \pm 8$ mosmol $/ \mathrm{kg}$ (both $P<0.01$ ). The urea clearance rate was estimated to be $1.6 \mathrm{ml} / \mathrm{min}$. For analysis of brain water content, a separate group of normal and nephrectomized rats was used. The brain water content of nephrectomized rats before hemodialysis was not significantly different from that of normals rats, while it increased by $8.0 \%$ after dialysis in the nephrectomized group dialyzed without urea $(P<0.05)$. In normal rats undergoing hemodialysis and in nephrectomized rats dialyzed with urea, no significant changes were observed in brain water content.

Diffusion-weighted images. Fig. 2 shows a typical set of diffusion-weighted images obtained from a nephrectomized rat after hemodialysis. As the diffusion-weighing increases, the 

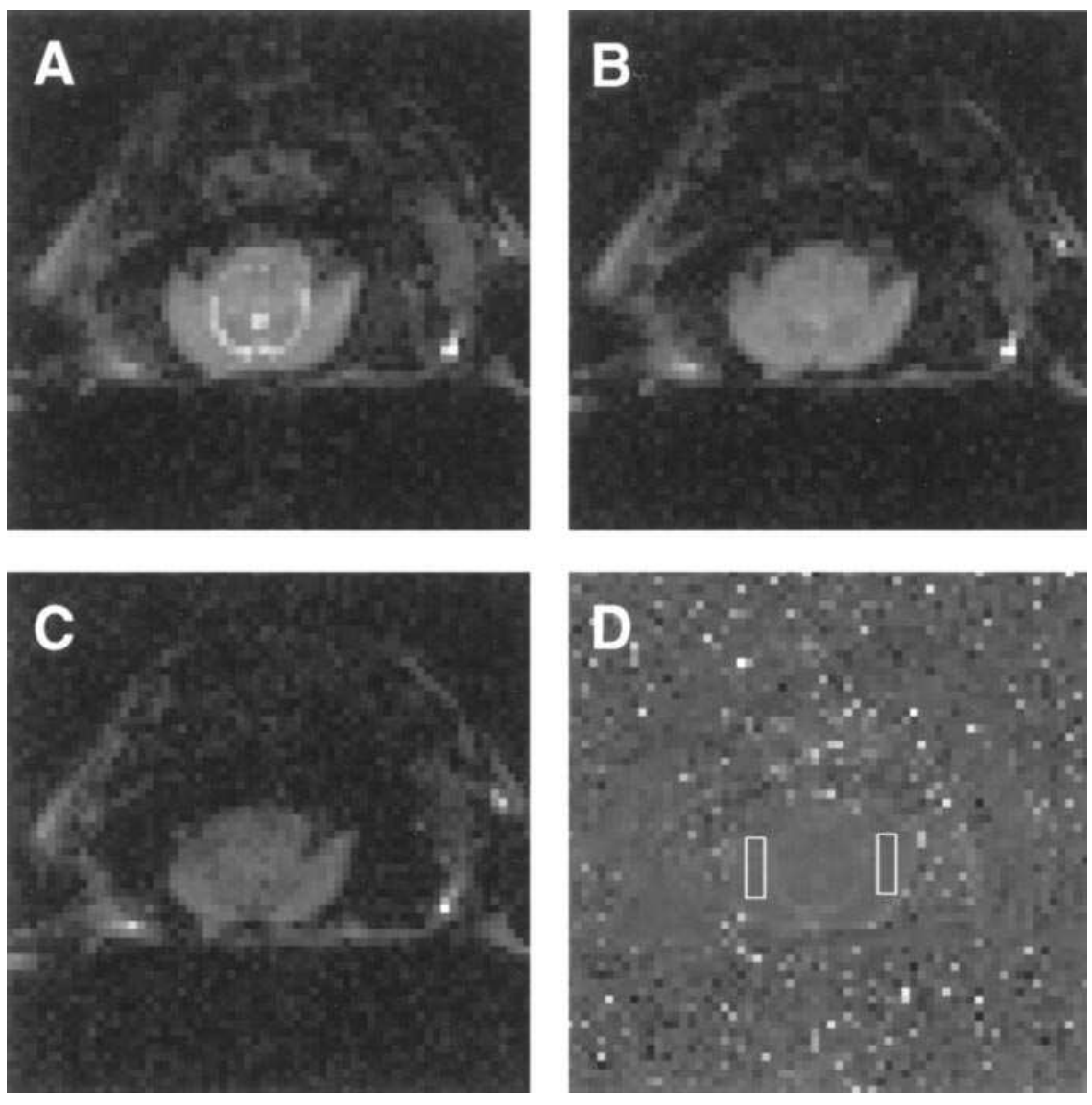

Figure 2. $(A-C)$ DWI of the brain of a nephrectomized rat after 90 min of hemodialysis obtained at gradient weighing factors $\mathrm{b}$ of $0.009 \times 10^{9} \mathrm{~s} / \mathrm{m}^{2}, 0.231 \times 10^{9} \mathrm{~s} / \mathrm{m}^{2}$, and $0.921 \times$ $10^{9} \mathrm{~s} / \mathrm{m}^{2}$, respectively. $(D)$ Apparent diffusion coefficient map generated by fitting the intensity of each pixel to the exponential decay given by Eq. 1 . The ROIs are indicated by white rectangles. The rat was placed in a prone position.

intensity of the image decreases (Fig. 2, $A-C$ ). The larger the diffusion, the more the signal will be attenuated. As an illustration, one can see that the bright signal originating from the CSF within the ventricles in Fig. $2, A-C$, is darkened faster than the surrounding tissues from the cerebral cortex. This is due to the higher diffusion of water in CSF, relative to cerebral cortex. The $\mathrm{D}_{a p p}$ map with the ROIs indicated by white rectangles is shown in Fig. $2 \mathrm{D}$. The structural details of the brain seen in Fig. $2 A$ can also be observed in the diffusion map reflecting the differences in $\mathrm{D}_{a p p}$. The visual inspection of the diffusion map shows a relative homogeneity of $\mathrm{D}_{a p p}$ values in the brain. In Fig. $2 D$, the main contrast arises from the CSF in the horseshoe-shaped region corresponding to the space between

Table II. Effect of Hemodialysis on Apparent Diffusion Coefficient in Normal and Nephrectomized Rats

\begin{tabular}{|c|c|c|c|}
\hline \multirow[b]{2}{*}{ Rat Groups } & \multirow{2}{*}{$\begin{array}{c}\text { Normal } \\
\text { dialyzed w/o urea } \\
n=6\end{array}$} & \multicolumn{2}{|c|}{ Nephrectomized } \\
\hline & & $\begin{array}{c}\text { dialyzed w/o urea } \\
n=6\end{array}$ & $\begin{array}{c}\text { dialyzed with urea } \\
n=5\end{array}$ \\
\hline & & $10^{-9} \mathrm{~m}^{2} / \mathrm{s}$ & \\
\hline Before nephrectomy & - & $0.85 \pm 0.09$ & $0.81 \pm 0.07$ \\
\hline Before hemodialysis & $0.84 \pm 0.09$ & $0.89 \pm 0.07$ & $0.84 \pm 0.07$ \\
\hline After hemodialysis & $0.80 \pm 0.07$ & $1.15 \pm 0.08^{* \ddagger}$ & $0.87 \pm 0.09$ \\
\hline
\end{tabular}

Values are means \pm SEM. $* P<0.01$ vs before hemodialysis and before nephrectomy; ${ }^{\ddagger} P<0.01$ vs normal, dialyzed w/o urea, or nephrectomized, dialyzed with urea. the midbrain and the cerebral hemispheres. The $\mathrm{D}_{\text {app }}$ in CSF is close to that of pure water at $37^{\circ} \mathrm{C}\left(3.25 \times 10^{-9} \mathrm{~m}^{2} / \mathrm{s}\right.$, (references 19,20$)$. There is a relatively low contrast between gray and white matter as the $\mathrm{D}_{a p p}$ for white matter is $\sim 87 \%$ of $\mathrm{D}_{a p p}$ for gray matter (12).

The results of brain $\mathrm{D}_{a p p}$ measurement before nephrectomy, and before and after hemodialysis performed $2 \mathrm{~d}$ after nephrectomy are shown in Table II. Values represent the means and SEM of the $\mathrm{D}_{a p p}$ of the selected regions for all rats in each group. It was found that the $\mathrm{D}_{a p p}$ was not affected by bilateral nephrectomy $(0.89 \pm 0.07$ vs $0.85 \pm 0.09$, and $0.84 \pm 0.07$ vs $0.81 \pm 0.07 \times 10^{-9} \mathrm{~m}^{2} / \mathrm{s}$, for groups $d$ and group $e$, respectively) or by hemodialysis in normal rats $(0.80 \pm 0.07$ vs $\left.0.84 \pm 0.09 \times 10^{-9} \mathrm{~m}^{2} / \mathrm{sec}\right)$. In nephrectomized rats, brain $\mathrm{D}_{\text {app }}$ was significantly increased after dialysis with non-urea bath $\left(1.15 \pm 0.08\right.$ vs $0.89 \pm 0.07 \times 10^{-9} \mathrm{~m}^{2} / \mathrm{s}, P<0.01$, group $\left.d\right)$, while no significant changes could be observed when rats were dialyzed with urea-containing dialysate $(0.87 \pm 0.09$ vs $0.84 \pm 0.07$ $\times 10^{-9} \mathrm{~m}^{2} / \mathrm{s}$, group $e$ ).

\section{Discussion}

Cerebral edema is responsible for most of the manifestation of dialysis disequilibrium syndrome. This has been confirmed both at autopsy and by computed tomography imaging of the brain in patients with renal failure who have undergone dialysis $(21,22)$. Several animal models of DDS have been developed and brain swelling has been reported in hemodialyzed dogs $(4,23)$ and rats $(14)$. In this study, we used a DWI approach to investigate both the nature and the mechanisms of 
the formation of the edema occurring in uremic rats undergoing hemodialysis. In terms of reduction of plasma urea level and osmolality, and increase of brain water content, our results of hemodialysis on uremic rats are essentially the same as those reported by Silver et al. (14). Recently, Arieff (2) argued that the rat model of hemodialysis could not be used as a model for DDS because the reduction rate of plasma osmolality was slower than that required to induce DDS in the dog. However, our studies confirmed that hemodialysis in uremic rats causes significant brain edema, while the same procedure has no effects on normal rats. This edema could be prevented by dialyzing the nephrectomized rats with a urea-containing bath. It is possible that the different results between the rat and dog are due to species differences. Our studies demonstrate that DWI techniques can be used to measure the changes in $\mathrm{D}_{a p p}$ of the brain water in rats undergoing dialysis.

As mentioned before, the nature of brain edema associated with DDS remains largely unknown. It has been classified as an intracellular/cytotoxic edema (5) as well as an extracellular/ osmotic edema (6). A primary mechanism underlying cytotoxic swelling is an impairment of the energy-dependent $\mathrm{Na}^{+}$/ $\mathrm{K}^{+}$pump whose normal role is to exclude $\mathrm{Na}^{+}$and hence water from the intracellular compartment $(20,24)$. A common example of cytotoxic brain swelling can be seen in patients suffering from ischemic stroke. The other type of edema, called osmotic edema, is defined as an abnormal increase of water content within the extracellular/interstitial compartment of the brain. It can be generated by an unfavorable osmotic gradient between the plasma and the interstitial or cerebrospinal fluids and, in the case of DDS, it could be generated by urea (6).

Our study, by measuring brain water $\mathrm{D}_{a p p}$, provides important information about the nature of edema in DDS. Because the brain contains different compartments of intracellular, extracellular, intravascular, and CSF components, the observed diffusion effect is a superposition of all the involved mobilities. By limiting our analysis to the cortical gray and white matter, it is possible to use a simple bicompartmental model of brain water where only extracellular and intracellular spaces are considered (12). In this model, the measured $\mathrm{D}_{a p p}$ is a volumeweighted average of the intracellular and extracellular diffusion coefficients $\left(\mathrm{D}_{i n}\right.$ and $\mathrm{D}_{e x}$, respectively).

$$
D_{a p p}=\frac{V_{i n} D_{i n}+V_{e x} D_{e x}}{V_{i n}+V_{e x}}
$$

where $\mathrm{V}_{\text {in }}$ and $\mathrm{V}_{\text {ex }}$ represent intracellular and extracellular volumes, respectively. While the exact values of intracellular and extracellular diffusion coefficients are not known, values for $\mathrm{D}_{\text {in }}$ and $\mathrm{D}_{e x}$ have been previously estimated (19). Intracellular water has a low coefficient (in the $0.3-0.4 \times 10^{-9} \mathrm{~m}^{2} / \mathrm{s}$ range), while the extracellular water has a coefficient close to that of pure water $\left(3.0-3.25 \times 10^{-9} \mathrm{~m}^{2} / \mathrm{s}\right.$ at $37^{\circ} \mathrm{C}$, reference 19$)$. Because of the difference between intra- and extracellular diffusion coefficients, DWI is able to discriminate between the two types of edema. Qualitatively, it can be seen that an increase of the extracellular volume (osmotic edema) will correspond to an increase in the $\mathrm{D}_{a p p}$ value, while an increase in the intracellular volume (cytotoxic edema) will correspond to a decrease in the measured $\mathrm{D}_{a p p}$. In the case of stroke, it was shown that the observed decrease in the $\mathrm{D}_{a p p}$ of water $(10,11,25)$ corresponded quantitatively with the known changes in relative intra- and extracellular volumes $(12,26)$. To calculate the rela- tive contribution of the fractional volume of extra- and intracellular space using Eq. 3, we used estimated values 0.35 $\times 10^{-9} \mathrm{~m}^{2} / \mathrm{s}$ for $\mathrm{D}_{i n}$, and $3.25 \times 10^{-9} \mathrm{~m}^{2} / \mathrm{s}$ for $\mathrm{D}_{e x}(19)$. With these parameters, we found that the $\mathrm{D}_{a p p}$ observed for the normal (group $a$ ) and uremic (group $d$ ) rats correspond to a fractional extracellular volume of about $17 \pm 3 \%$ and $19 \pm 3 \%$, respectively. The fact that there were no differences in brain water content and $\mathrm{D}_{a p p}$ between normal and uremic rats is expected as brain edema has never been observed in uremic animals $(14,27)$ or humans $(28)$. In the same manner, we calculated that the $29 \%$ increase in the $\mathrm{D}_{a p p}$ value observed in rats dialyzed in the absence of urea $\left(1.15 \pm 0.08\right.$ vs $0.89 \pm 0.0710^{-9}$ $\mathrm{m}^{2} / \mathrm{s}$ ) would correspond to an increase of $\sim 47 \%$ of the fractional extracellular volume within the selected regions (from 19 to $28 \%$ ). This increase in extracellular water could be partially accounted for by the observed $8.0 \%$ increase of the total brain water. Because $\mathrm{D}_{i n}$ and $\mathrm{D}_{e x}$ are only estimated values, these calculations are speculative. However, the combination of the two results (i.e., the increase of $\mathrm{D}_{a p p}$ and the increase in the total brain water content) strongly suggest that the incoming water is accumulating in the extracellular compartment. The increase of extracellular space could be driven by an increase in CSF volume due to an initial gradient in osmolarity between plasma and CSF after hemodialysis $(1,4)$. The fact that $\mathrm{D}_{\text {app }}$ was found to increase strongly argues against a cytotoxic type of edema in DDS, which has been shown to be associated with a decrease in the $\mathrm{D}_{a p p}$ due to an intracellular-extracellular volume shift (12). Moreover, cytotoxic edemas are known to be correlated with an accumulation of lactate characteristic of hypoxic/ischemic conditions. Such conditions have not been reported in animals treated with rapid dialysis $(23,29)$.

The physiological mechanisms leading to the formation of brain edema due to DDS have been the object of conflicting reports. It was first attributed to a gradient in the urea content between plasma and brain occurring during acute hemodialysis due to a faster removal of plasma urea than brain urea. The "reverse urea effect" introduced by Pappius et al. (4) was supported by several other laboratories reporting higher urea concentrations in the CSF than plasma $(1,30)$. Moreover, DDS could be partially corrected by maintaining plasma osmolality during dialysis by adding urea (31) or mannitol (32), or by increasing sodium concentration of the dialysate (33). In contrast, Arieff et al., reported a predominant role for the brain intracellular $\mathrm{pH}$ in the pathogenesis of DDS. Based on the observation that rapid dialysis induced a fall in the $\mathrm{pH}$ of CSF and the gray matter in animals with renal failure (29), they suggested that the formation of idiogenic osmoles associated with an increased $\mathrm{H}^{+}$activity was responsible for the edema formation (2, 29). Recently, Silver et al. (14) reported that, in uremic rats dialyzed without urea, there was a $53 \%$ decrease in plasma urea, but only a $13 \%$ decrease in brain urea. The retention of urea in the brain could account for the increased water content. When uremic rats were dialyzed with urea, there were no changes in either plasma or brain urea contents, and there was no brain edema. We used the similar hemodialysis protocol and confirmed that urea bath essentially prevented brain edema from occurring and was associated with no changes in brain water $\mathrm{D}_{a p p}$. Therefore, our results support a major role for the "reverse urea hypothesis" in the pathogenesis of cerebral edema in DDS.

In conclusion, our results show that the hemodialysis of uremic rats leads to an increase in the $\mathrm{D}_{a p p}$ of the cerebral cor- 
tex along with an increase in the brain water content. These findings are consistent with an increase in the extracellular water that characterizes an interstitial edema of the brain. These changes were not observed when the nephrectomized rats were dialyzed with urea-containing dialysate, suggesting that DDS is due to a reverse urea gradient. Up to now, DDS in end-stage renal disease patients is diagnosed by exclusion of other possible central nervous abnormalities (3). The DWI technique described here could potentially be used for clinical diagnosis of DDS and would enhance our understanding of pathogenesis of DDS in the end-stage renal disease patients.

\section{Acknowledgments}

The authors thank Ms. Bethany Skovan for her expert technical assistance.

This work was supported by the National Institutes of Health research grant DK-45666 and a grant from the Southern Arizona Foundation (both to Y.H. Lien).

\section{References}

1. Kennedy, A.C., A.L. Linton, and J.C. Eaton. 1962. Urea levels in cerebrospinal fluid after hemodialysis. Lancet. i:410-411.

2. Arieff, A.I. 1994. Dialysis disequilibrium syndrome: current concepts on pathogenesis and prevention. Kidney Int. 45:629-635.

3. Mahoney, C.A., and A.I. Arieff. 1982. Uremic encephalopathies: clinical, biochemical and experimental features. American Journal of Kidney Disease. 2: 324-336.

4. Pappius, H.M., J.H. Oh, and J.B. Dossetor. 1967. The effects of rapid hemodialysis on brain tissues and cerebrospinal fluid of dogs. Can. J. Physiol. Pharmacol. 45:129-147.

5. Fishman, R.A., and P.H. Chan. 1980. Metabolic basis of brain edema. In Advances in Neurology. Vol. 28, Brain Edema. J. Cervos-Navarro and R. Ferszt, editors. Raven Press, New York. 207-215.

6. Milhorat, T.H. 1987. Classification of brain swelling and edemas. In Cerebrospinal Fluid and the Brain Edemas. T.H. Milhorat, editor. Neuroscience Society of New York, NY. 75-100.

7. Le Bihan, D., R. Turner, and C.T.W. Moonen. 1991. Imaging of diffusion and microcirculation with gradient sensitization: design, strategy and significance. J. Magn. Reson. Imaging. 1:7-28.

8. Le Bihan, D., E. Breton, D. Lallemand, P. Grenier, E. Cabanis, and M. Laval-Jeantet. 1986. MR imaging of intravoxel incoherent motions: application to diffusion and perfusion in neurologic disorders. Radiology. 161:401-407.

9. Warach, S., J. Gaa, B. Siewert, P. Wielopolski, and R.R. Edelman. 1995. Acute human stroke studied by whole brain echo planar diffusion-weighted magnetic resonance imaging. Ann. Neurol. 37:231-241.

10. Moseley, M.E., J. Kucharczyk, J. Mintorovitch, Y. Cohen, J. Kurhanewicz, N. Derugin, H. Asgari, and D. Norman. 1990. Diffusion weighted MR imaging of acute stroke: correlation with T2-weighted and magnetic susceptibility-enhanced MR imaging in cats. Am. J. Neuroradiol. 11:423-429.

11. Moseley, M.E., Y. Cohen, J. Mintorovitch, L. Chileuitt, H. Shimizu, J. Kucharczyk, M.F. Wendland, and P.R. Weinstein. 1990. Early detection of regional cerebral ischemia in cats: comparison of diffusion- and T2-weighted MRI and spectroscopy. Magn. Reson. Med. 14:330-346.
12. Van Gelderen, P., M.H.M. de Vleeschouwer, D. Despres, J. Pekar, P.C.M. van Zijl, and C.T.W. Moonen. 1994. Water diffusion and acute stroke. Magn. Reson. Med 31:154-163.

13. Mori, S., and P.C.M. van Zijl. 1995. Diffusion weighing by the trace of the diffusion tensor within a single scan. Magn. Reson. Med. 33:41-52.

14. Silver, S.M., J.A. DeSimone, D.A. Smith, and R.H. Sterns. 1992. Dialysis disequilibrium syndrome (DDS) in the rat: role of the reverse urea effect. Kidney Int. 42:161-166.

15. Lien, Y.H., J.I. Shapiro, and L. Chan. 1990. Effects of hypernatremia on organic brain osmoles. J. Clin. Invest. 85:1427-1435.

16. Bernt, E., and H.U. Bergmeyer. 1965. Urea. In Methods in Enzymatic Analysis. H.U. Bergmeyer, editor. Academic Press, Inc., New York. 401-406.

17. Ordidge, R.J., J.A. Helpern, Z.X. Qing, R.A. Knight, and V. Nagesh. 1994. Correction of motional artifacts in diffusion-weighted MR images using navigator echoes. Magn. Reson. Imaging. 12:445-460.

18. Anderson, A.W., and J.C. Gore. 1994. Analysis and correction of motion artifacts in diffusion weighted imaging. Magn. Reson. Med. 32:379-387.

19. Van Zijl, P.C.M., D. Davis, and C.T.W. Moonen. 1994. Diffusion spectroscopy in living system. In NMR in Physiology and Biomedicine. R.J. Gillies, editor. Academic Press, Inc., San Diego, CA. 185-198.

20. Benveniste, H., L.W. Hedlund, and G.A. Johnson. 1992. Mechanism of detection of acute cerebral ischemia in rats by diffusion-weighted magnetic resonance microscopy. Stroke. 23:746-754.

21. La Greca, G., S. Biasioli, S. Chiaramonte, P. Dettori, A. Fabris, M. Feriani, V. Pinna, E. Pisani, and C. Ronco. 1982. Studies on brain density in hemodialysis and peritoneal dialysis. Nephron. 31:146-150.

22. Peterson, H.D. 1964. Acute encephalopathy occurring during hemodialysis. Arch. Intern. Med. 113:887-890.

23. Arieff, A.I., S.G. Massry, A. Barrientos, and C.R. Kleeman. 1973. Brain water and electrolyte metabolism in uremia: effects of slow and rapid dialysis hemodialysis. Kidney Int. 4:177-187.

24. Djuricic, B.M., D.V. Micic, and B.B. Mrsulja. 1984. Phase recognition of edema cause by ischemia. In Recent Progress in the Study and Therapy of Brain Edema. K.G. Go and A. Baethman, editors. Plenum Publishing Corp. New York. 491-498.

25. Minematsu, K., L. Li, M. Fisher, C.H. Sotak, M.A. Davis, and M.S. Fiandaca. 1992. Diffusion-weighted magnetic resonance imaging: rapid and quantitative detection of focal brain ischemia. Neurology. 42:235-240.

26. Latour, L.L., K. Svoboda, P. Mitra, and C.H. Sotak. 1994. Time-dependent diffusion of water in a biological model system. Proc. Natl. Acad. Sci. USA 91:1229-1233.

27. Mahoney, C.A., A.I. Arieff, W.J. Leach, and V.C. Lazarowitz. 1983. Central and peripheral nervous system effects of chronic renal failure. Kidney Int. 24:170-177.

28. Basile, C., J.D. Miller, Z.J. Koles, and M. Grace. 1987. The effects on brain water and EEG in stable chronic uremia. American Journal of Kidney Disease. 9:462-469.

29. Arieff, A.I., R. Guisado, S.G. Massry, and V.C. Lazarowitz. 1976. Central nervous system $\mathrm{pH}$ in uremia and the effects of hemodialysis. J. Clin. Invest. 58:306-311.

30. Rosen, S.M., K. O’Connor, and S. Shaldon. 1964. Hemodialysis disequilibrium. Br. Med. J. 2:672-675.

31. Kennedy, A.C., A.L. Linton, R.G. Luke, S. Renfrew, and A. Dinwoodie. 1964. The pathogenesis and prevention of cerebral disfunction during dialysis. Lancet. i:790-793.

32. Rodrigo, F., J. Shideman, R. McHugh, T. Buselmeier, and C. Kjellstrand. 1977. Osmolality changes during hemodialysis. Natural history, clinical correlations, and influence of dialysate glucose and intravenous mannitol. Ann. Intern. Med. 86:554-561.

33. Port, F.K., W.J. Johnson. and D.W. Klass. 1973. Prevention of dialysis disequilibrium syndrome by use of high sodium concentration in the dialysate. Kidney Int. 3:327-333. 